\title{
Phylogeography and genetics of the globally invasive snail Physa acuta Draparnaud 1805, and its potential to serve as an intermediate host to larval digenetic trematodes
}

\author{
Erika T. Ebbs ${ }^{*}$, Eric S. Loker and Sara V. Brant
}

\begin{abstract}
Background: Physa acuta is a globally invasive freshwater snail native to North America. Prior studies have led to conflicting views of how P. acuta populations are connected and genetic diversity is partitioned globally. This study aims to characterize phylogeographic and population genetic structure within the native range of $P$. acuta, elucidate its invasion history and assess global patterns of genetic diversity. Further, using meta-analytic methods, we test the 'Enemy-Release hypothesis' within the P. acuta - digenetic trematode system. The 'Enemy-Release hypothesis' refers to the loss of native parasites following establishment of their host within an invasive range. Population genetic data is combined with surveys of trematode infections to map range-wide trematode species richness associated with $P$. acuta, and to identify relevant host-population parameters important in modeling host-parasite invasion.

Results: Phylogenetic analyses using mtDNA uncovered two major clades (A \& B). Clade A occurs globally while clade B was only recovered from the Western USA. All invasive populations sampled grouped within Clade A, where multiple independent source populations were identified from across North America. Significant population genetic structure was found within the native range of $P$. acuta, with some evidence for contemporary geographic barriers between western and eastern populations. Mito-nuclear discordance was found suggesting historical isolation with secondary contact between the two mitochondrial clades. Trematode species richness was found to differ significantly between native and invasive populations, in concordance with the 'Enemy-Release hypothesis'. Further, our data suggests a positive relationship between nucleotide diversity of invasive populations and trematode prevalence and richness.

Conclusions: This study includes a wider geographic sampling of $P$. acuta within its native range that provides insight into phylogeographic and population genetic structure, range-wide genetic diversity and estimation of the invasion history. Meta-analysis of P. acuta - trematode surveys globally is consistent with the 'Enemy-Release hypothesis'. Additionally, results from this study suggest that host demographic parameters, namely genetic diversity as a proxy for population size, may play an essential role in how parasite communities assemble within invasive host populations. This knowledge can be used to begin to construct a framework to model host-parasite invasion dynamics over time.
\end{abstract}

Keywords: Invasion genetics, Physa, Physidae, Mitochondrial marker, Trematode, Parasite invasion, Parasite richness, Enemy-release

\footnotetext{
* Correspondence: gendron@unm.edu

Department of Biology, Museum of Southwestern Biology Parasite Division,

Center for Evolutionary and Theoretical Immunology, University of New

Mexico, 167 Castetter MSCO3 2020, Albuquerque, NM 87131, USA
}

(c) The Author(s). 2018 Open Access This article is distributed under the terms of the Creative Commons Attribution 4.0 International License (http://creativecommons.org/licenses/by/4.0/), which permits unrestricted use, distribution, and reproduction in any medium, provided you give appropriate credit to the original author(s) and the source, provide a link to the Creative Commons license, and indicate if changes were made. The Creative Commons Public Domain Dedication waiver (http://creativecommons.org/publicdomain/zero/1.0/) applies to the data made available in this article, unless otherwise stated. 


\section{Background}

Invasive species are an important consequence of global change [1], therefore understanding their origin and invasion history [2], as well as how genetic variation is partitioned across their range [3], is vital. Population genetics provides a powerful tool by which invasion processes can be revealed [2, 4]. Freshwater gastropods present an interesting case, as they are often dispersed passively and distributed patchily [5] in nature, but human activities (i.e. aquaria trade, boats) may greatly alter dispersal, population structure and consequently evolutionary dynamics $[5,6]$.

One such invader is Physa acuta [7], a globally invasive freshwater snail native to North America [8, 9], which now occurs on all continents except Antarctica $[10,11]$. Remarkable reproductive plasticity has been reported within $P$. acuta, specifically in populations' ability to alter the number of generations per year [12, 13], a characteristic that might contribute to the invasion success of $P$. acuta. Physa acuta is known to displace native gastropods to become the dominant species over very short periods of time [14-16]. For example, doubling times as short as 4 weeks have been recorded from European (invasive) P. acuta populations [17].

The invasion history of $P$. acuta is muddled by two centuries of taxonomic confusion (summarized by Wethington and Lydeard [10]), due in large part to plasticity in shell phenotype and overestimation of nominal diversity. Consequently, the timing of invasion and the connectivity of native and invasive populations remain unclear. Interestingly, Physa acuta was first described from its invasive range in France [7] over two centuries ago and it was not until 12 years later that it was described by Say [18] from Pennsylvania, USA, under a different name, Physa heterostropha. Nominal diversity of $P$. acuta-like snails reached at least eight species [19-21] prior to the inclusion of molecular genetic data [10, 22, 23]. Molecular genetic studies in addition to reproductive isolation experiments $[8,24]$ demonstrated the need to synonymize $P$. heterostropha (North America), P. virgata (North America), P. integra (North America) and P. cubensis (Central and South America) to a single species, Physa acuta [7]. Taylor [21] placed $P$. acuta and closely allied species into the genus Haitia, based primarily on penial morphology, which has demonstrated phylogenetic utility $[10,21]$. However, a molecular phylogeny [10] has shown that Haitia in the sense of Taylor [21] is not monophyletic. Molecular phylogenetic analyses have also supported that $P$. acuta occurs globally [10].

Efforts have been made to elucidate the population genetic structure of $P$. acuta at both regional [25-28] and global $[11,25]$ scales. These studies reconstructed the genetic structure of $P$. acuta primarily in its invasive range in Europe, with limited sampling from native populations. Characterizing population structure within the native range is foundational to resolving invasion history [29]. Limited sampling from native populations limit possible hypotheses relative to a likely invasion history scenario and identification of source populations. Further, those prior studies have presented conflicting results of how genetic varation is partitioned globally, and specifically whether genetic diversity is homogenous among native and invasive populations [11, 25, 28]. The primary objective of this study was to address current gaps in our knowledge of the genetic distribution of $P$. acuta by chacterizing range-wide population genetic and phylogeographic patterns, and reconstruct its invasion history.

Apart from its remarkable distribution, $P$. acuta offers a unique lens to understand host-parasite invasion dynamics, which are complex and largely overlooked [30-32]. Physid snails are important intermediate hosts to digenetic trematodes (Platyhelminthes, Digenea) [33, 34]. More broadly, snails act as first and second intermediate host to a large proportion of trematodes, over 10,000 species [35]. Despite the several papers discussing parasites in invasive species, surprisingly little is known about how host population dynamics might influence the invasion processes of their associated parasites [31, 32]. Following invasion, host species are expected to lose their associated trematode assemblages [36]. Parasite loss has been attributed to host invasive success, as per the 'Enemy-Release hypothesis' [37], which posits that release of regulation by natural enemies contributes to the rapid establishment of invasive populations. It is also expected that invasive hosts may acquire a new indigenous parasite assemblage within their invasive range. What shapes the assembly of the new parasite community is unclear [31]. Here we measure $P$. acuta-trematode species richness globally to test for release of digenetic trematodes within invasive populations and secondarily test for correlations among trematode infections and host population genetic parameters to identify factors that maybe relevant to host-parasite invasion, and discuss a framework to use these data to being to model invasion dynamics.

\section{Methods}

\section{Specimen collection}

Physa acuta populations were sampled opportunistically, between 1998 and 2015, to document the biodiversity of their trematode parasites. The specimens used in this study were collected from across North America (native range) as well as several invasive localities (locality details in Additional files 1 and 2) and represent $P$. acuta over a 17-year period (Fig. 1).

Snails were collected primarily from the waters edge using a mesh sieve or plucked from vegetation. The snails were first screened for trematode infection by 


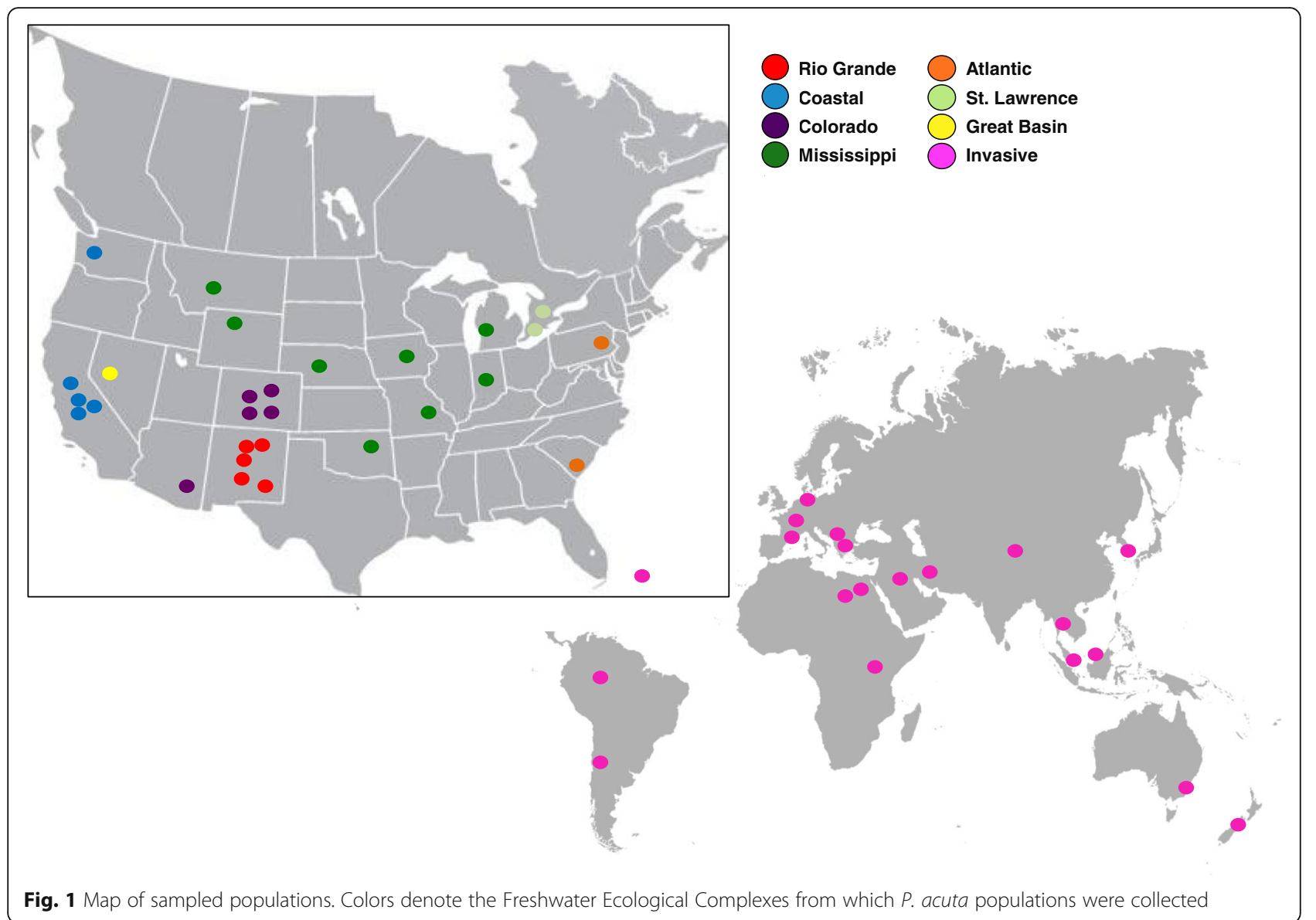

leaving an individual snail overnight in the well of a 24-well cell culture plate filled with artificial spring water. Snails were considered infected upon visual confirmation of mobile trematode larvae (cercariae) using a dissection microscope. Cercariae and their snail hosts, as well as uninfected snails, were isolated and stored in 95\% ethanol and deposited into the Museum of Southwestern Biology (MSB), Division of Parasites (Additional files 1 and 2).

To improve geographic sampling and ensure we were working with a monophyletic species, specimens from this study were combined in phylogenetic analyses with known $P$. acuta sequences published in the NCBI GenBank database (Additional file 1). The latter sequences were published between 2004 and 2016, from both native and invasive populations, and 159 physid sequences were downloaded and included in this study.

\section{DNA extraction and PCR amplification}

A small piece of tissue was taken from the head foot of individual snails. DNA was extracted using the E.Z.N.A. Mollusc DNA kit (Omega Biotek) following the manufacturer's protocol.
We sequenced two mitochondrial DNA loci ( $\operatorname{cox} 1$ and $16 S)$ as they are the most abundant genetic markers available in the NCBI database and have been used successfully to recover population genetic variation within $P$. acuta $[10,22]$. We also sequenced a nuclear locus (ITS1) to assess the potential for mito-nuclear discordance of the recovered subclades.

We sequenced 509 bases of the cox 1 gene using the universal primers, LCO11490: 5'-GGTCAACAAATCAT AAAGATATTGG-3' and LCO2198: 5'TAAACTTCA GGGTGACCAAAAAATCA-3' [38] and 469 bp of $16 \mathrm{~S}$ rDNA using Brh: 5'-CCGGTCTGAACTCAGATCA CGT-3' and Arl: 5'-CGCCTGTTTAACAAAAACAT -3' [39]. Additionally we sequenced the complete (495 bp) ITS1 internal transcribed spacer region (ITS-1S: $5^{\prime}$ - CCAT GAACGAGGAATTCC CAG-3', 5.8AS: 5' -TTAG CAAACCGACCCTCAGAC $-3^{\prime}$ ) of a subset of the $P$. acuta individuals chosen to represent the recovered mitochondrial clades. Sequencing reactions were performed using the BigDye sequencing kit 3.1 (Applied Biosystems, Foster City, California, USA). Sequences were edited using Sequencher 5.3 (Gene Codes Corporation, Ann Arbor, MI, USA), and then aligned using ClustalW [40] and further aligned manually if 
necessary. GBlocks [41] was used to identify and remove difficult to align regions present within both the ITS1 and $16 S$ alignments. Sequences generated during this study were submitted to GenBank under the accession numbers MF694400-MF694492, MG001330-MG001338 (Additional files 1 and 2). All alignments used in this study were deposited into TreeBase (www.treebase.org).

\section{Phylogenetic analyses}

Phylogenetic analyses of Physa species were performed for the purposes of determining the in-group in all subsequent phylogeographic and population genetic analyses. Aplexa elongata was used as an out-group [10]. Physa phylogenetic datasets were analyzed separately as $\operatorname{cox} 1$ (509 bp), 16S (611 bp) and $\operatorname{cox} 1+16 S$ (1120 bp). Relatively few ITS1 (525 bp) sequenes exist within the NCBI database (Additional files 1 and 2), and were therefore unavailable to be used in a concatenated analyses of Physa species. The T92 + G model of nucleotide substitution was used to model the cox1, 16S, and ITS1 datasets, and $\mathrm{HKY}+\mathrm{G}$ was used to model the cox $1+16 \mathrm{~S}$ dataset. Models were chosen based on the Akaike information criterion (AIC [42]) using JModelTest2 [43].

Phylogenetic analysis of Physa species did not recover a supported sister clade for P. acuta, therefore Physa spelunca was chosen as an out-group based on Wethington and Lydeard [10] and was used to root subsequent in-group analyses. Samples accessioned in NCBI that were identified as $P$. acuta via BLASTn search but had a genetic distance greater than $5 \%$ (distance between $P$. acuta and $P$. spelunca) were excluded from in-group analyses. In-group analyses included 151 individual snails and were performed to evaluate phylogeographic patterns within $P$. acuta. Each locus was treated as an independent dataset and analyzed separately. Optimal models of nucletotide substitiution were found to be the same per gene region as used for phylogenetic analysis of Physa.

Maximum Likelihood (ML), Minimum Evolution (ME) and Bayesian Inference (BI) were performed on each phylogenetic dataset. ME and ML analyses were performed in the program PAUP* 4.0 [44]. One thousand bootstrap replicates were performed within each gene tree analysis to statistically assess the resulting topologies.

Bayesian Inference (BI) was performed using the program MrBayes v. 3.2.6 [45], consisting of two replicated runs for each locus with four Markov chain Monte Carlo (MCMC) chains, one cold and three heated chains. Each analysis ran for 10,000,000 generations and was sampled every 1000 generations. The analysis was terminated when the standard deviation of the split frequencies was or fell below 0.01, supporting convergence. Likelihood parameters and convergence between runs were assessed using the program Tracer v.1.6 [46], based on EES values greater than 200. The first 2500 trees from each analysis were discarded as burnin. Resulting phylogenetic trees were visualized and manipulated using Fig Tree v. 1.3 [47] and MEGA 6 [48].

Recovered topologies were statistically compared to a null phylogenetic hypothesis $\left(H_{O}\right)$ using an approximately unbiased (AU) test [49], where per site likelihood scores were bootstrapped (10,000 replications) using the program CONSEL [50] to generate $p$-values. To test the 'single source' hypothesis we constrained all invasive individuals as monophyletic, with an Eastern USA origin $\left(H_{O}{ }^{1}\right)$, using the $\operatorname{cox} 1$ dataset. Secondly, to test for mito-nuclear discordance within P. acuta, we constrained the ITS1 topology for complete concordance with recovered mitochondrial topologies $\left(H_{O}{ }^{2}\right)$. Constrained trees were created in Mesquite [51]. Per site likelihood scores were calculated in PAUP* [44] .

\section{Genetic diversity and population structure}

To characterize range-wide population genetic diversity and structure we grouped native populations according to the freshwater ecological complex (FWEC [52]) from which they were collected. FWECs are based on delineations of freshwater ecoregions determined by fish distribution [53]. FWEC's are a subset of ecoregions and are designated based on major habitat type and biological distinctiveness. We sampled 8 of the 10 North American FWECs [52]. We selected between 2 and 10 individual $P$. acuta from each population to be used for genetic analysis.

Genetic diversity summary statistics of $P$. acuta populations were estimated using DNAsp v. 5 [54] based on the $\operatorname{cox} 1$ and $16 S$ gene regions; number of unique haplotypes $(h)$, number of segregating (polymorphic) sites $(S)$, average number of nucleotide differences (K), haplotype diversity $(H d)$, nucleotide diversity $(\pi)$ and Watterson's estimator $\left(\Theta_{\mathrm{w}}\right.$, per site) were calculated. The dataset of 151 individual $P$. acuta cox 1 sequences consisted of 88 unique haplotypes. A minimum spanning network was constructed to view connections among haplotypes using the program PopART [55], http://popart.otago.ac.nz/). Relationships among haplotypes (185 bases) were also evaluated using $\mathrm{BI}$, to determine ancestral relationships among haplotypes. Parameters for BI were identical to those used in analyses described previously.

To estimate overall range-wide genetic structuring of $P$. acuta (cox1) a one-way Analysis of Molecular Variance test (AMOVA [56]) was performed in Arlequin v. 3.5 [57]. Populations were partitioned by five geographical regions (North America, Eurasia, South America, Africa, and Australasia): $\Phi_{\mathrm{CT}}$ estimates variation among the five regions sampled, $\Phi_{\mathrm{SC}}$ estimates variation among localities within the regions and $\Phi_{\mathrm{ST}}$ estimates variation from all 
samples across all localities sampled. A second AMOVA was preformed to assess population genetic structure within the native range of $P$. acuta partitioned by sampling localities and the eight FWECs sampled.

To further evaluate population genetic structure within $P$. acuta, pairwise $\Phi_{\mathrm{ST}}[58]$ values were estimated from the cox 1 dataset. Significance of $\Phi_{\mathrm{ST}}$ values $(p<0.05)$ was determined by permutation tests of 10,000 random permutations, calculated in Arlequin v. 3.5 [57].

Pairwise uncorrected $p$-distances were calculated for cox1, $16 S$ and ITS1 datasets within and between FWEC, countries within the invasive range, within and between the invasive and native ranges, and within and between recovered clades identified through MSN and phylogenetic analysis using MEGA 6 [48].

\section{Demographic analysis}

We estimated changes in the effective population size $(\mathrm{Ne})$ over time by fitting a Bayesian Skyline demographic model (BSP [59]) for each FWEC/geographic region, recovered clades and the total cox 1 dataset in "BEAST v. 1.7.0 [60]. The HKY substitution model was used for two simultaneous MCMC runs for between 3000,000 and $80,000,000$ iterations sampling between every 3000 and 10,000 steps. Analyses were run using three mutation rates of 1e-4 (0.04\%), 1e-6 (1\%) and 4e-6 (4\%) per million year, chosen to reflect a range of possible rates of cox 1 evolution based on other gastropod systems [61-64]. Convergence was checked (ESS of 200 or greater) and results visualized using Tracer v.1.6 [46]. BSP data from each analyzed dataset generated in Tracer v. 1.6 was exported and visualized in Microsoft Excel for comparison.

\section{Invasion history and meta-analysis of the trematodes of $P$. acuta}

In conjunction with the molecular data generated by this study, a literature search was carried out to compile reports of $P$. acuta outside of North America.

ISI Web of Knowledge was searched for 1) all reports of $P$. acuta outside of North America and 2) surveys of trematode assemblages of $P$. acuta within both its native and invasive range. Data complied was published from 1805 up to the end of 2016, and recovered using combinations of keywords; Physa acuta, Physa, Physella, Costella, Haitia, trematode, parasites, invasive gastropod, malacological survey, trematode survey and cercarial survey. Further, studies cited by recovered articles were also included. In total the final dataset included 196 published reports of Physa acuta outside of North America and 7 trematode surveys from the native range of $P$. acuta and 15 within its invasive range. Physa acuta trematode surveys carried out by the authors for the purposes of this study were also added to the meta-dataset. From each trematode survey, observed species richness $\left(S_{o}\right)$ and prevalence $(p r$, percentage of patent infections) were calculated. $S_{o}$ is defined as the number of different trematode species occurring within a surveyed host population [65]. Because of the difficulties associated with identifying larval trematodes a conservative approach to calculating $S_{o}$ was taken: 'species' were considered unique based on trematode family. Consequently, reported measures of $S_{o}$ from the native range are likely underestimates $[34,66]$. Only patent infections, where trematode cercariae were being shed, were considered as infected. Evidence of metacercaria (trematode cysts) within $P$. acuta were not included as the relationships between trematodes and invertebrate second intermediate hosts are generally less specific [67, 68]. Genetic results from this study were used to assign host population parameters as regional estimates for each study used within the meta-analysis. For example, population genetic estimates from African populations were assigned to all $P$. acuta trematode surveys undertaken in Africa. Australasian samples were excluded from these analyses due to small sample size. Estimates of haplotype diversity $(H d)$ and nucleotide diversity $(\pi)$, were assigned as population parameters. Time since invasion $(t s i)$ was estimated by assigning each surveyed population into an 'invasion phase' category: phase $4:<80$ years since invasion, phase 3: $80-180$ years since invasion, phase $2: 180-280$ years since invasion and phase 1: $280+$ (native range). 'Invasion phases' were determined based on published reports of $P$. acuta invasions and genetic evidence provided by this study. Pairwise correlation analyses of $S_{o}$, tsi and $p r$ with $H d, \pi$, and $\theta$ were evaluated using Pearson's correlation coefficient. $p$-values were adjusted for multiple comparisons using both Bonferroni and Benjamini-Hochberg corrections [69].

\section{Results}

\section{Phylogenetic analyses}

Cox1, 16S, 16S + cox1 and ITS1 gene tree analyses (Additional files 3, 4, 5 and 6) of Physa species demonstrate that samples included in this study form a clade with $P$. acuta sequences published in the NCBI database (Additional files 1 and 2), and represent a single globally distributed species. All phylogenetic analyses failed to resolve sister relationships to $P$. acuta, similar to the findings of Wethington and Lydeard [10].

In-group analyses demonstrate phylogenetic structuring (Fig. 2, Additional file 6) and revealed two clades, referred to hereafter as clade A and clade B. Clades were moderately supported statistically for ME and ML analyses (cox1, 89/82; 16S, 89/88) and posterior probabilities from BI were strong $(\operatorname{cox} 1,1 ; 16 S, 1)$. Clade A $(n=123)$ is the larger, containing all invasive populations sampled in 

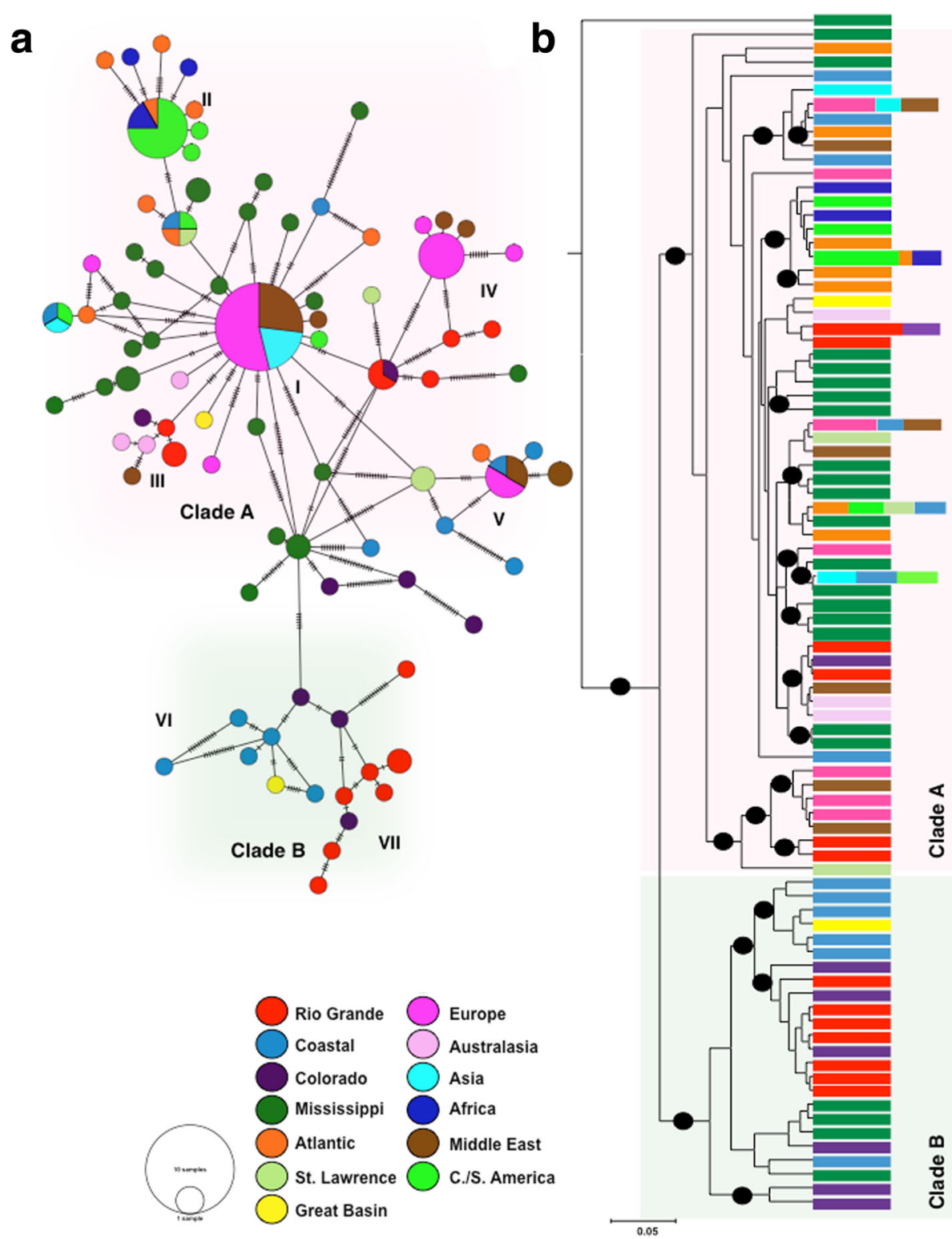

Fig. 2 Relationships of recovered cox 1 haplotypes. a. minimum spanning network of 88 P. acuta haplotypes. The network is shaded to depict the split between clade A (pink) and B (green), within each clade haplogroups are denoted as I -VII. b. BI phylogeny of all 88 haplotypes. Nodes with a posterior probability of $\geq 95 \%$ are denoted by a black circle. Haplotypes are colored by the FWEC from which they were collected

addition to populations recovered across the native range. While some individuals from clade $\mathrm{A}$ and $\mathrm{B}$ were found sympatrically in the Western USA, clade B $(n=26)$ was only recovered west of the Rocky Mountains. Clades A and B were not recovered from the ITS1 phylogeny, possibly suggesting mito-nuclear discordance (Additional file 5).

Phylogenetic analyses of the P. acuta in-group largely lacked resolution for terminal nodes across all genes samples. We therefore employed approximately unbiased topology tests to more robustly assess phylogenetic hypotheses. Using this method we rejected the null hypotheses of a single invasive origin $\left(H_{O}{ }^{1}, p=2 \mathrm{e}-7\right)$ and of strict concordance of mitochondrial clades $\mathrm{A}$ and $\mathrm{B}$ within the ITS1 dataset $\left(H_{O}^{2}, p=3 \mathrm{e}-5\right)$.

\section{Genetic diversity and population structure}

Indices of genetic diversity (cox1 and 16S) for each population sampled are summarized in Table 1. In comparing native to invasive range, greater genetic diversity $\left(H d_{\text {native }}=\right.$ $\left.0.97, H d_{\text {invasive }}=0.615 ; \quad \pi_{\text {native }}=0.0289, \quad \pi_{\text {invasive }}=0.0098\right)$ was found within the native range. Haplotype diversity is consistently high among FWECs sampled, often reaching 100\% (Colorado, Coastal, Great Basin, Atlantic). 
Within the cox 1 and $16 S$ datasets, 88 and 43 unique haplotypes were recovered, respectively. More genetic variability was recovered from the cox 1 dataset and haplotype relationships were estimated by constructing a Minimum Spanning Network (MSN; Fig. 2a). The MSN corroborates the split of clades A and B, however it also suggests that haplogroups may be further substructured. FWEC's do not appear to be a primary factor in shaping the genetic structure of $P$. acuta. Clade A contains all of the sampled invasive haplotypes. Many of the haplogroups within clade A (I-V) are connected by haplotypes recovered from the Eastern United States (Mississippi and Atlantic FWECs), indicating that these regions are likely a source of invasions from the native range of $P$. acuta.

Clade B shows greater nucleotide diversity than clade A (even when invasive haplotypes are removed, $\pi_{\text {CladeA }}=$ $0.019, \pi_{\text {CladeB }}=0.024$ ). All haplotypes were recovered from the Western United States (west of the Rocky Mountains). While sampling is not sufficient to know if Clade B is truly geographically restricted, our data suggest (1) clade B is a Western USA clade and (2) FWEC's may play a greater role in shaping western populations of $P$. acuta (Fig. 2a, haplogroups VI and VII).

Relationships among haplotypes were also examined using BI analysis (Fig. 2b). Haplotype relationships are identical to those observed from the MSN, and the divergence of clade A and B is supported with 100\% posterior probability. Invasive haplotypes group with multiple source populations, from across the native range. Together the MSN and BI analyses of haplotypes suggest that there have been several distinct invasion events to the Eastern Hemisphere from multiple sources across North America.

Overall population genetic structure of $\operatorname{cox} 1$ was evaluated by AMOVA (Table 2). Both range-wide and native-range AMOVA's suggest a significant $\Phi_{\mathrm{SC}}$ and $\Phi_{\mathrm{ST}}(p<0.001$ and $p<0.001$, respectively). In the native range $76.55 \%$ of genetic variation is attributed to within population variation, indicating that overall FWEC's, and the biogeographic regions tested in general, are not important in structuring $P$. acuta populations.

Pairwise uncorrected $p$-distances within and between populations of $P$. acuta were calculated from the cox 1 dataset (Table 3). Within the native range within population genetic distance averages $0.0292(\sim 3 \%)$, relative to $0.0102(\sim 1 \%)$ within the invasive range which are significantly lower $(p=0.0006)$. Within population genetic distances between the Western USA and Eastern USA (native range) vary significantly $(p=0.05)$, and average $0.0346(\sim 3.5 \%)$ and $0.022(2.2 \%)$ respectively. Overall western populations exhibit the highest within population genetic distances while Africa and Asia demonstrate the lowest $(x=0.004,0.4 \%)$.
Pairwise genetic distances and $\Phi_{\mathrm{ST}}$ values were calculated (Table 3) and assessed statistically (only significance values for $\Phi_{\mathrm{ST}}$ are shown). The Mississippi FWEC, the largest complex sampled, shows significant $(p<0.05)$ genetic differentiation from four of the six other FWECs (Rio Grande, Coastal, Colorado and Atlantic) as well from Africa and Middle East. Similarly, the Atlantic FWEC shows significant $(p<0.05)$ genetic differentiation from four of the six other FWECs (Rio Grande, Coastal, Colorado and Mississippi) as well from Europe, Australasia, Asia and the Middle East.

\section{Demographic and invasion history analyses}

Bayesian Skyline Plots (Fig. 3, Additional file 7) estimated changes in effective population sizes over coalescent time. Results based on a $1 \%$ change per million year rate of $\operatorname{cox} 1$ evolution (Fig. 3) largely matched estimates using 0.04 and $4 \%$ change per million year (Additional file 7). Regionally (Fig. 3a) $\mathrm{Ne}$ is greatest within North America and has been stable over the past 60,000 years. Populations from the invasive range suggest much smaller effective sizes, congruent with previous analyses of genetic diversity. Eurasian and African/Australasian populations indicate a possible recent population expansion. When Clades A and $\mathrm{B}$ are compared (Fig. 3b), Clade A and the total $P$. acuta cox1 dataset suggests a recent population decline which is likely an artifact of population subdivision. Heller et al. [70] showed subdivision can confound coalescent estimators of $\mathrm{Ne}$ and result in an erroneous signal of population decline. There is no evidence (Fig. 3c) of population decline within the native range. There is evidence to suggest that Clade B has recently undergone a demographic expansion (within the past 10,000 years), both clades $\mathrm{A}$ and $\mathrm{B}$ have comparatively similar contemporary $\mathrm{Ne}$.

\section{Invasion timeline and meta-analysis of the trematodes of $P$. acuta}

Based on reports from the literature an invasion timeline is summarized in Fig. 4 (full bibliographic information can be found in Additional file 8). Findings from this literature search informed subsequent time since invasion analysis.

Physa acuta trematode surveys from both the native $(n=7)$ and invasive $(n=15)$ range were complied to estimate range-wide species richness (Table 4). Average $S_{o}$ within the native range $\left(S_{o}=3.25\right)$ was significantly greater $(p=0.0016)$ than within the invasive range $\left(S_{o}=\right.$ 0.3125). Western European $(n=2)$ and Iranian $(\mathrm{n}=1)$ populations of $P$. acuta were the only invasive populations surveyed where patent infections were reported. Prevalence varied significantly $(p=0.04)$ among invasive $(0.00319 \%)$ and native ranges $(0.2 \%)$. Variables were analyzed using Pearson's correlation coefficient $(\rho)$, 
Table 1 Summary of range-wide population statistics, cox 1

\begin{tabular}{|c|c|c|c|c|c|c|c|c|}
\hline Region/Population & FWEC & $\mathrm{N}$ & $\mathrm{H}$ & $\mathrm{Hd}$ & S & K & $\pi$ & $\Theta w$ \\
\hline \multicolumn{9}{|l|}{ Native Range } \\
\hline \multicolumn{9}{|l|}{ USA } \\
\hline Gila River, AZ & $\mathrm{COL}$ & 3 & & & & & & \\
\hline Denver Area, CO & $\mathrm{COL}$ & 2 & & & & & & \\
\hline Fremont Co., CO & $\mathrm{COL}$ & 2 & & & & & & \\
\hline Chaffee Co., CO & $\mathrm{COL}$ & 1 & & & & & & \\
\hline Gafield Co., CO & $\mathrm{COL}$ & 1 & & & & & & \\
\hline Mesa Co., CO & $\mathrm{COL}$ & 1 & & & & & & \\
\hline Rio Blanco Co., CO & $\mathrm{COL}$ & 1 & & & & & & \\
\hline Yuma Co., CO & $\mathrm{COL}$ & 1 & & & & & & \\
\hline Total & & 12 & 11 & 0.98 & 54 & 17.16 & 0.0337 & 0.035 \\
\hline Woodward Park, CA & COA & 8 & & & & & & \\
\hline Los Banos WMA, CA & $\mathrm{COA}$ & 2 & & & & & & \\
\hline Coyote Creek, CA & $\mathrm{COA}$ & 3 & & & & & & \\
\hline Total & & 13 & 13 & 1 & 69 & 18.45 & 0.0363 & 0.044 \\
\hline New Harmony, IN & MIS & 2 & & & & & & \\
\hline Okoboji Lake, IA & MIS & 1 & & & & & & \\
\hline Reynolds County, MO & MIS & 1 & & & & & & \\
\hline Medicine Lake, MN & MIS & 1 & & & & & & \\
\hline Bench Creek Pond, MT & MIS & 10 & & & & & & \\
\hline Mormon Lake, NE & MIS & 12 & & & & & & \\
\hline Big Horn River, WY & MIS & 1 & & & & & & \\
\hline Stillwater, OK & MIS & 5 & & & & & & \\
\hline Total & & 24 & 21 & 0.989 & 86 & 13.93 & 0.02736 & 0.0453 \\
\hline Stillwater NWR, NV & GRB & 2 & & & & & & \\
\hline Total & & 2 & 2 & 1 & 20 & 20 & 0.0393 & 0.0393 \\
\hline Carson Nat. Fr., NM & $\mathrm{RIO}$ & 3 & & & & & & \\
\hline Bosque Del Apache, NM & $\mathrm{RIO}$ & 9 & & & & & & \\
\hline Shady Lakes, NM & $\mathrm{RIO}$ & 2 & & & & & & \\
\hline Bitter Lake, NM & $\mathrm{RIO}$ & & & & & & & \\
\hline Total & & 13 & 12 & 0.987 & 49 & 14.65 & 0.0278 & 0.029 \\
\hline Philadelphia, PA & ATL & 2 & & & & & & \\
\hline Charles Towne Landing SP, SC & ATL & 7 & & & & & & \\
\hline Total & & 9 & 9 & 1 & 33 & 10.58 & 0.021 & 0.024 \\
\hline \multicolumn{9}{|l|}{ Canada } \\
\hline Point Peele NP, ON & STL & 1 & & & & & & \\
\hline Niagra River, ON & STL & 3 & & & & & & \\
\hline Total & & 4 & 3 & 0.833 & 14 & 8.167 & 0.016 & 0.015 \\
\hline NR Total & & 73 & 68 & 0.973 & 45.29 & 14.74 & 0.0289 & 0.033 \\
\hline \multicolumn{9}{|l|}{ Invasive Range } \\
\hline Cuba & $\mathbb{I R}$ & 3 & & & & & & \\
\hline Chile & IR & 10 & & & & & & \\
\hline Lake Titicaca, Peru & $\mathbb{R}$ & 1 & & & & & & \\
\hline
\end{tabular}


Table 1 Summary of range-wide population statistics, cox1 (Continued)

\begin{tabular}{|c|c|c|c|c|c|c|c|c|}
\hline Region/Population & FWEC & $\mathrm{N}$ & $\mathrm{H}$ & $\mathrm{Hd}$ & $S$ & K & $\pi$ & $\Theta w$ \\
\hline C\&S AM Total & & 14 & 6 & 0.604 & 13 & 2.879 & 0.0056 & 0.008 \\
\hline Kisumu, Kenya & $\mathbb{R}$ & 4 & & & & & & \\
\hline AF Total & & 4 & 3 & 0.833 & 5 & 2.5 & 0.00493 & 0.005 \\
\hline France & IR & 4 & & & & & & \\
\hline Greece/Macadonia & IR & 23 & & & & & & \\
\hline Netherlands & $\mathbb{I R}$ & 1 & & & & & & \\
\hline EU Total & & 28 & 7 & 0.696 & 35 & 8.132 & 0.016 & 0.0177 \\
\hline New Zealand & $\mathbb{I R}$ & 1 & & & & & & \\
\hline Australasia & IR & 2 & & & & & & \\
\hline NZ/OZ Total & & 3 & 3 & 1 & 9 & 6 & 0.0118 & 0.012 \\
\hline South Korea & IR & 1 & & & & & & \\
\hline Thailand & IR & 1 & & & & & & \\
\hline Singapore & IR & 3 & & & & & & \\
\hline Maylasia & $\mathbb{I R}$ & 3 & & & & & & \\
\hline AS Total & & 7 & 2 & 0.286 & 6 & 1.714 & 0.0034 & 0.005 \\
\hline Iraq & $\mathbb{I R}$ & 2 & & & & & & \\
\hline Iran & IR & 12 & & & & & & \\
\hline MD Total & & 14 & 7 & 0.813 & 29 & 8.66 & 0.017 & 0.018 \\
\hline IR Total & & 70 & 28 & 0.615 & 16.16 & 4.98 & 0.0098 & 0.011 \\
\hline Global Total & & 143 & 96 & 0.794 & 30.725 & 9.86 & 0.0193 & 0.023 \\
\hline
\end{tabular}

Regional abbreviations: NR native range, IR invasive range, C\&S AM Central and South America, AF Africa, EU Europe, NZ/OZ New Zealand and Australia, MD Middle East, FWEC refers to Freshwater Ecological Complexes; COL Colorado FWEC, COA Coastal FWEC, MISS Mississippi FWEC, GRB Great Basin FWEC, RIO Rio Grande FWEC, ATL Atlantic FWEC and STL St. Lawrence FWEC. Population statistic abbreviations: $N$ number of individuals sampled, $H$, number of haplotypes, $H d$, haplotype diversity, $S$, segregating sites, $K$, average sequence divergence, $\pi$, nucleotide diversity, $\Theta w$, Wattersons estimator per site, Italicized numbers refer to population averages. $\left.{ }^{*}\right)$ Indicates a statistically significant value $(P<0.05)$

summarized in Table 5. All comparisons between So, tsi, $p r$ and the demographic variables $(H d, \pi, \theta)$ resulted in significant unadjusted $p$-values, with the exception of $p r$ and $H d$. To correct for multiple comparisons, $p$-values were adjusted using $\mathrm{BH}$ and Bonferroni methods (Table 5). Following adjustment, So, tsi and $p r$ were found to significantly correlate with $\pi$ and $\theta\left(\mathrm{p}_{\mathrm{BH}}=0.003, \mathrm{p}_{\mathrm{BH}}=0.000\right.$, $\mathrm{p}_{\mathrm{BH}}=0.033$, respectively). $\pi$ and $\theta$ were found to have a correlation coefficient of 1 (Table 5). There is a strong positive relationship between $t s i, \pi(\rho=0.97)$ and $S o(\rho=0.8)$

Table 2 Analysis of Molecular Variance

\begin{tabular}{|c|c|c|c|c|}
\hline Source of Variation & d.f. & $\%$ Variation & Fixation indices & $p$ value \\
\hline \multicolumn{5}{|l|}{ Range Wide } \\
\hline Among Regions & 6 & 3.19 & $\Phi C T=0.093$ & 0.183 \\
\hline $\begin{array}{l}\text { Among Populations } \\
\text { within Regions }\end{array}$ & 28 & 27.3 & DSC $=0.282$ & $<0.001$ \\
\hline Within Populations & 110 & 69.52 & DST $=0.305$ & $<0.001$ \\
\hline \multicolumn{5}{|l|}{ Native Range } \\
\hline Among Regions & 6 & 4.27 & $\Phi C T=0.043$ & 0.228 \\
\hline $\begin{array}{l}\text { Among Populations } \\
\text { within Regions }\end{array}$ & 14 & 19.18 & DSC $=0.20$ & $<0.001$ \\
\hline Within Populations & 55 & 76.55 & DST $=0.235$ & $<0.001$ \\
\hline
\end{tabular}

and a moderate correlation with $p r(\rho=0.57)$, supporting the prediction that genetic diversity increases with time since invasion. In total, these results suggest a significant relationship between background genetic variation, a proxy for population size, and the richness of trematode assemblages.

\section{Discussion}

\section{Range wide population genetic patterns}

Our results propose different population genetic patterns between the native and invasive range of $P$. acuta. While haplotype diversity within the invasive range is not low relative to other invasive snails, like Melanoides tuberculata [6] or Haminoea japonica [71] within their invasive ranges, by comparison there is an approximately $20 \%$ reduction in $H d$ relative to the native range. Our analyses reveal that invasive populations have substantially less mtDNA diversity relative to native populations (Table 1), a finding supported by numerous studies of invasive gastropods $[6,71]$. Interestingly however, this result is in contrast to recently published work on $P$. acuta. Bousset et al. [11] used 9 microsatellite loci to estimate range-wide patterns of genetic diversity and reported no difference in neutral genetic variation between 
Table 3 Pairwise genetic distances and $\Phi_{\text {ST }}$ values

\begin{tabular}{|c|c|c|c|c|c|c|c|c|c|c|c|c|c|}
\hline & 1 & 2 & 3 & 4 & 5 & 6 & 7 & 8 & 9 & 10 & 11 & 12 & 13 \\
\hline 1. Rio Grande & 0.03 & 0.0673 & 0.0167 & 0.1571 & 0.2818 & 0.17422 & -0.0706 & 0.2668 & 0.2396 & 0.2926 & 0.377 & 0.2613 & 0.0288 \\
\hline 2. Coastal & 0.0366 & 0.0386 & 0.05412 & 0.08 & 0.1557 & 0.0269 & -0.2006 & 0.1841 & 0.1509 & 0.1573 & 0.2607 & 0.129 & -0.0085 \\
\hline 3. Colorado & 0.0338 & 0.0398 & 0.0363 & 0.1694 & 0.3058 & 0.1857 & -0.0897 & 0.3418 & 0.24643 & 0.35611 & 0.4045 & 0.3038 & 0.0623 \\
\hline 4. Mississippi & 0.34 & 0.0364 & 0.0387 & 0.0288 & 0.0969 & 0.01138 & 0.022 & 0.0983 & 0.0745 & 0.00036 & 0.245 & 0.0662 & -0.0125 \\
\hline 5. Atlantic & 0.0356 & 0.0364 & 0.0418 & 0.0283 & 0.0214 & 0.0773 & 0.2032 & 0.1869 & 0.17405 & 0.1216 & 0.0944 & 0.1189 & 0.0199 \\
\hline 6. St. Lawrence & 0.0295 & 0.0305 & 0.0348 & 0.0241 & 0.0211 & 0.0166 & 0.1199 & 0.0586 & 0.2199 & 0.2518 & 0.4667 & -0.006 & -0.0158 \\
\hline 7. Great Basin & 0.031 & 0.0328 & 0.0346 & 0.0327 & 0.0337 & 0.0281 & 0.0333 & 0.2469 & 0.2587 & 0.4986 & 0.4948 & 0.2333 & -0.135 \\
\hline 8. Europe & 0.0298 & 0.0325 & 0.0366 & 0.0251 & 0.023 & 0.0175 & 0.0288 & 0.0165 & 0.1726 & 0.0994 & 0.3923 & 0.0291 & 0.0932 \\
\hline 9. Australasia & 0.031 & 0.035 & 0.0373 & 0.025 & 0.022 & 0.0186 & 0.0311 & 0.0184 & 0.012 & 0.4158 & 0.6129 & 0.1178 & -0.0355 \\
\hline 10. Asia & 0.0249 & 0.027 & 0.0318 & 0.017 & 0.0143 & 0.0116 & 0.0233 & 0.012 & 0.01 & 0.003 & 0.7128 & 0.0567 & 0.13 \\
\hline 11. Africa & 0.0343 & 0.036 & 0.0414 & 0.0277 & 0.016 & 0.02 & 0.0327 & 0.0221 & 0.02 & 0.01375 & 0.005 & 0.383 & 0.2029 \\
\hline 12. Middle East & 0.0317 & 0.0332 & 0.0378 & 0.0258 & 0.0228 & 0.0178 & 0.031 & 0.0181 & 0.019 & 0.0124 & 0.0228 & 0.0187 & 0.06245 \\
\hline 13. S. \& C. America & 0.0311 & 0.0323 & 0.038 & 0.0243 & 0.0146 & 0.0173 & 0.0286 & 0.019 & 0.0174 & 0.0103 & 0.0056 & 0.0195 & 0.0058 \\
\hline
\end{tabular}

Pairwise within and between FWEC/region genetic distances are shown in the lower diagonal. Within genetic distances are italicized. Pairwise $\Phi_{\text {ST }}$ values are shown in the upper diagonal, values with a $p$-value $\leq 0.05$ are bolded

the native and invasive ranges. These contradictory results are likely explained by the fact that the Bousset et al. [11] study was limited to five native populations, four of which were from the Eastern USA where many invasive haplotypes likely originated. Consequently, Bousset et al. [11] did not recover similar amounts of genetic diversity revealed by this study. Discordance of mtDNA and microsatellite data is not uncommon [72] and both reveal aspects of invasion history. Mitochondrial markers can often better detect subtle genetic subdivision, due to reduced effective population size and lack of recombination [72-74]. Consequently, a genealogical approach utilizing mtDNA markers is frequently used to characterize population genetic structure and identify source populations [6, 71, 75]. Our findings based largely on mtDNA, combined with those of Bousset et al. [11], suggest $P$. acuta is overall a genetically diverse species, relative to other invasive gastropods $[6,76,77]$. However, this study reports significant

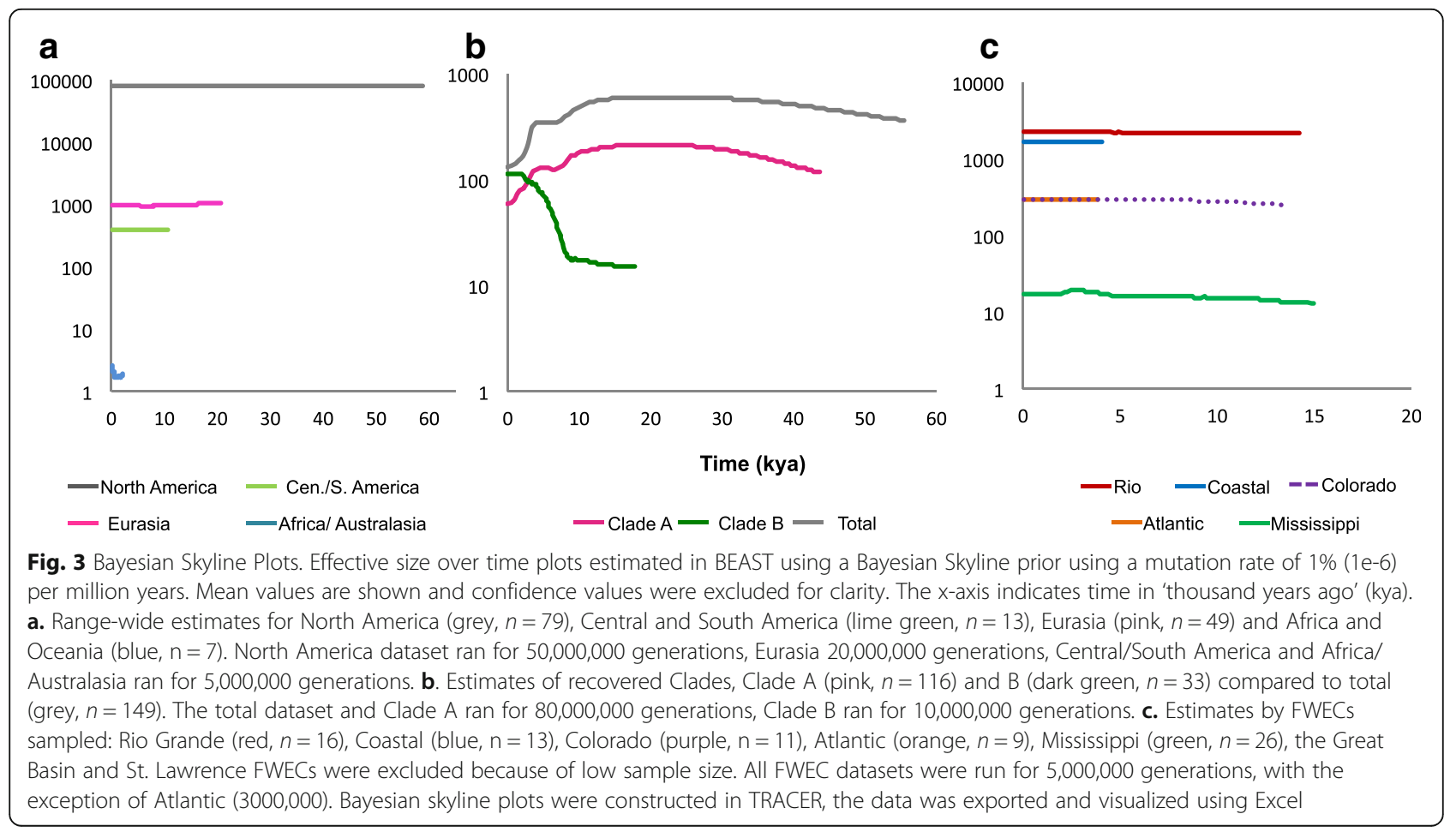




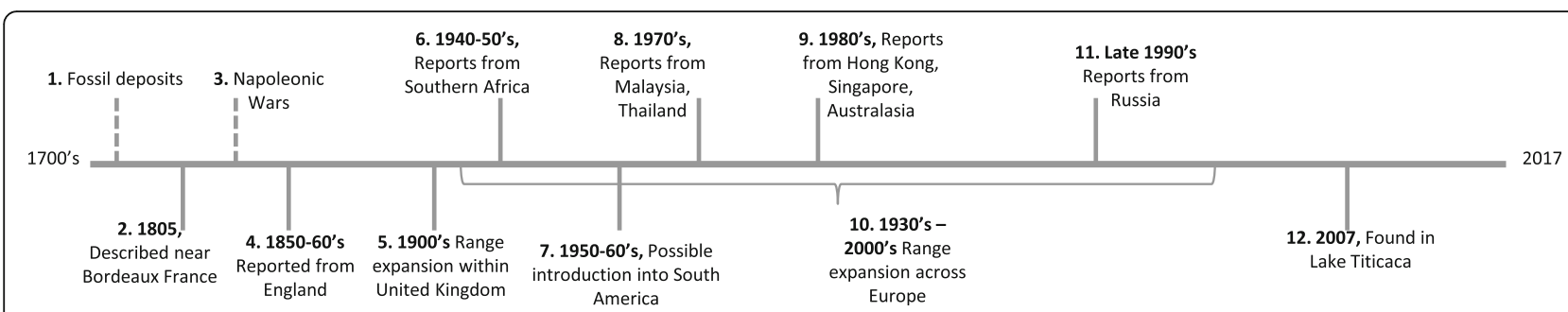

Fig. 4 Invasion timeline of Physa acuta. 1. Absence of Physa acuta shells from European fossil deposits older than 18 ${ }^{\text {th }}$ Century [115]. 2. Described by Draparnaud [7] near Bordeaux, France. Anderson [87] posits likelihood of introduction from Mississippi USA via the cotton trade. 3. Trade between USA and France ends during Napoleonic wars, trade with England and USA begins. 4. First reports of $P$. acuta in England [88, 89]. 5. Reports of $P$. acuta all over United Kingdom by the later half of $20^{\text {th }}$ Century [116-119] 6-12. Primary citations for these reports are listed in Additional File 7

genetic structuring within the native range and between some native and invasive populations that has not been previously reported by other investigators. Further, previously unknown mito-nuclear discordance (Fig. 2, Additional files 5 and 6) suggests historical isolation followed by secondary contact has likely occurred among native Western and Eastern North American populations.

\section{Genetic structure within the native range and biogeographic considerations}

Previous studies have hypothesized an Eastern USA origin for $P$. acuta $[8,11]$. Our data suggest that sampled genetic diversity is comparable (marginally greater in Western USA) across the native range with evidence of geographic structuring between the Eastern and Western USA populations. Phylogenetic analyses suggest the

Table 4 Reports of infection and trematode species richness of Physa acuta as first intermediate

\begin{tabular}{|c|c|c|c|c|c|}
\hline Country & Citation & \# Individuals Surveyed & \# Patent Infections & Prevalence & So \\
\hline \multicolumn{6}{|l|}{ Native Range } \\
\hline New Mexico (Bosque del Apache) & This study & 1200 & 78 & 0.065 & 5 \\
\hline New Mexico (Eagles Nest) & This study & 65 & 5 & 0.07 & 2 \\
\hline Nebraska & This study & 120 & 16 & 0.13 & 4 \\
\hline Montana & This study & 165 & 3 & 0.018 & 2 \\
\hline Wyoming & This study & 26 & 8 & 0.31 & 1 \\
\hline Colorado & This study & 300 & 5 & 0.017 & 3 \\
\hline Mexico & Barragán-Sáenz et al. 2009 & 496 & 109 & 0.22 & 5 \\
\hline \multicolumn{6}{|l|}{ Invasive Range } \\
\hline New Zeland & Mitchell \& Leung 2015 & 810 & 0 & 0 & 0 \\
\hline Benin & Ibikounlé et al. 2009 & 345 & 0 & 0 & 0 \\
\hline Czech Republic & Faltýnková 2005 & 57 & 0 & 0 & 0 \\
\hline Egypt & Abo-Madyan et al. 2005 & na & 0 & 0 & 0 \\
\hline Egypt & Bin Dajem 2009 & 704 & 0 & 0 & 0 \\
\hline Egypt & Dahesh \& Farid & na & 0 & 0 & 0 \\
\hline France & Gerard et al. 2003 & 413 & 1 & 0.0024 & 1 \\
\hline Germany & Faltýnková and Hass 2006 & 141 & 0 & 0 & 0 \\
\hline Iceland & Skinnerson et al. 2008 & 737 & 0 & 0 & 0 \\
\hline Iran & Athari et al. 2006 & 3560 & 8 & 0.0022 & 1 \\
\hline Kenya & Loker \& Laidemitt, unpublished data & 589 & 0 & 0 & 0 \\
\hline Morocco & Laamrani et al. 2005 & na & 0 & 0 & 0 \\
\hline New Zeland & This study & 1480 & 0 & 0 & 0 \\
\hline Spain & Toledo et al. 1998 & 2717 & 1 & 0.00037 & 1 \\
\hline Zambia & Phiri et al. 2007 & 9 & 0 & 0 & 0 \\
\hline
\end{tabular}


Table 5 Matrix of correlation coefficients.

\begin{tabular}{lllllll}
\hline & $S_{O}$ & $t s i$ & $p r$ & $H d$ & $\pi$ & $\Theta$ \\
\hline$S_{O}$ & & 0.8 & 0.77 & 0.54 & 0.76 & 0.77 \\
$t s i$ & $\mathbf{0 . 0 0 2 5}$ & & 0.57 & 0.46 & 0.97 & 0.98 \\
$p r$ & $\mathbf{0 . 0 0 3 9}$ & $\mathbf{0 . 0 3 2 *}$ & & 0.44 & 0.55 & 0.56 \\
$H d$ & 0.0614 & 0.06 & 0.096 & & 0.5 & 0.5 \\
$\pi$ & $\mathbf{0 . 0 0 3}$ & $\mathbf{0}$ & $\mathbf{0 . 0 3 3 ^ { * }}$ & 0.061 & & 1 \\
$\Theta$ & $\mathbf{0 . 0 0 3}$ & $\mathbf{0}$ & $\mathbf{0 . 0 3 3 ^ { * }}$ & 0.061 & $\mathbf{0}$ &
\end{tabular}

Pearson's correlation coefficients are shown in the upper diagonal and corresponding $p$-values, adjusted using Benjamini-Hochberg $(\mathrm{BH})$ correction, are shown in the lower diagonal. $p$-values $\leq 0.05$ are bolded. *Indicates $p$-values that significant under the $\mathrm{BH}$ correction, but not significant under the more conservative Bonferroni correction

existence of two clades (A \& B) within the native range, interestingly these clades are sympatric in the Western USA, while clade B appears to be restricted to Western USA. Field surveys and subsequent molecular analysis reveal that individuals belonging to clade $\mathrm{A}$ and/or $\mathrm{B}$ can be collected side by side from the same water body in New Mexico, Colorado, California and Nevada. Phylogenetic analysis (Additional files 3, 4, 5 and 6) did not result in sufficient resolution to reveal the geographic origin of $P$. acuta, however increased sampling of western populations fails to support the Eastern origin hypothesis $[8,9,11]$. Several individuals (S94 \& S22) collected from California (Coastal FWEC) and one (S17) from New Mexico (Rio Grande FWEC) were close matches genetically to $P$. acuta, but for $\operatorname{cox} 1$ had greater than $5 \% p$-distance, our designated in-group cut-off. Additionally the presumed sister species $P$. spelunca has only been recovered from Wyoming [78] and did not have support as the sister species to $P$. acuta from our analyses. Anecdotally, recent molecular genetic studies of Physa [79-81] may demonstrate a greater number of independent taxonomic units from Western waterways relative to the Eastern USA, suggesting that biogeographically the west may have been important in physid diversification.

This study is the first to compare and assess discordance among nuclear and mitochondrial markers within P. acuta. Discordance between ITS1 and mitochondrial phylogenies could suggest incomplete lineage sorting, though more likely is a recent history of genetic exchange between once isolated populations. Clades A \& B were not recovered from the ITS1 gene tree (Additional file 5), and when the largely unresolved ITS1 phylogeny was constrained to match the mitochondrial topology a significantly $(p=3 \mathrm{e}-5)$ worse phylogeny was recovered. Gene trees of the non-recombining mitochondrial markers may suggest historical isolation between the Western and Eastern USA. It may be hypothesized that the Rocky Mountains, or associated waterways, have played a role in restricting gene-flow, which has been shown relevant in structuring populations of other freshwater organisms [82-84]. It can also be hypothesized that anthropogenic dispersal within North America or subsequent re-introduction from the invasive range into the Western USA, has led to reticulation of the two clades [85], and contemporary admixture within the Western USA. Another possible line of evidence supporting this hypothesis is the recent discovery of two distinct mitochondrial genomes, varying in size (Isolate A 14,490 vs Isolate B, 14,314 bp) and 37 indels, collected from the same pond in New Mexico [86]. cox1, 165 and ITS1 sequence from Nolan et al. [86] was included in our phylogenetic dataset and consistently parse out with clade A (Isolate A) and B (Isolate B). At this time there has been no investigation into the biological relevance or functional consequences of Isolate A versus B. Mitochondrial genome divergence may in fact be a relic of once isolated populations conferring no functional differences. The fact that invasive haplotypes have only been recovered from clade $\mathrm{A}$ is an intriguing pattern warranting further investigations.

\section{Invasion history of Physa acuta}

Figure 4 summarizes records of $P$. acuta globally (see Additional file 8 for full bibliographic information). These records, combined with population genetic inference, lead to a hypothesized route of invasion. The first record of $P$. acuta outside of North America was its initial description in France in 1805 [7], over 200 years ago. It is has been hypothesized by others, and supported genetically here, that these were the first invasive populations of $P$. acuta. Anderson [87] was the first to posit that the $P$. acuta discovered by Draparnaud [7], in the Bordeaux region of France, were introduced via the cotton trade from Mississippi USA during the $18^{\text {th }}$ century. Trade between France and the USA ceased during the Napoleonic wars and began between USA and England, where records of $P$. acuta appear in the mid 1800's [88, 89]. Western Europe (England and France) likely maintained the first invasive populations of $P$. acuta. However, less than 100 years later, populations were reported from Eastern Europe, Africa, Asia, South America, the Middle East, the Caribbean, New Zealand and Australia. Prior studies have suggested that the subsequent global invasion resulted from the spread of early Western European colonizers [87, 90]. If this was the case we would expect 1) clustering of all invasive populations with Western European haplotypes and 2) a stepping stone like model of haplotype relationships [91, 92]. This model was not supported by any of the performed population genetic analyses and further, an approximately unbiased (AU) [49] topology test specifically rejected the monophyly of invasive populations $(p=2 \mathrm{e}-7)$. 
Our data supports that there have been multiple independent invasions into Western Europe, likely from different sources (Fig. 2). Data from this study suggest that some European populations are closely allied with populations in Asia and the Middle East and share the most common invasive haplotype. We infer that this shared haplotype [93] is related to the initial invasive populations of $P$. acuta in Western Europe roughly 200 years ago, and has subsequently spread east. It is more parsimonious to hypothesize that genetically depauperate European populations expanded east than to assume that identical haplotypes from a genetically diverse source (North America) founded three distinct invasive regions.

Samples from Africa, South America and the Caribbean are related and are likely the result of an independent invasion event, though it is currently not possible to determine the directionality without more samples. Physa acuta invasions into Africa have been more recent relative to European invasions. Extensive malacological surveys across the African continent suggest the African invasion occurred in the range of 1940-50's, with populations reported from South Africa [15, 94, 95], Namibia [96], Morocco [97], Nigera [98], and Kenya [99]. Records suggest a similar time frame for the South American and Caribbean invasion [100, 101]. Surveys by Albrecht et al. [102] suggest that Lake Titicaca (Peru \& Bolivia) was colonized 20 years ago.

Our data suggests haplotype connections between invasive populations and Clade A individuals collected in the Western and Eastern USA and Canada. While our data supports the initial invasions from the Southeastern USA to Western Europe, we also find evidence of haplotype connections between the Coastal FWEC (California) and the Middle East and Eastern Europe. Currently, based on our sampling it is unclear if there are in fact Western source populations, or if this relationship is the result of the re-introduction of invasive $P$. acuta from other continents into the Western USA. Our data supports that all source populations have originated from Clade A, however, it remains unclear if Western haplotypes of Clade A originated from the Eastern USA or are the result of secondary contact from invasive populations, though these scenarios are not mutually exclusive. Increased sampling within the western range is necessary to fully elucidate the source of Clade A members recovered from the Western USA. Founding events, within and from the native range, are likely the result of the aquaria or aquatic plant trade as posited by multiple investigators $[11,15,87,103]$.

\section{Host-parasite invasion dynamics}

Combining published reports of $P$. acuta occurrence with our genetic data we found a significant relationship between genetic diversity ( $\pi$ and $\theta$ ) and trematode prevalence $(p r)$, and richness $\left(S_{O}\right)$. Nucleotide diversity $(\pi)$ is a better measure of background genetic variation than haplotype diversity, as it is more robust to the stochastic effects of drift [104]. Higher values of haplotype diversity relative to nucleotide diversity were recovered from the invasive range suggesting rapid expansion from founding populations [104].

We also found that time since invasion (tsi) significantly correlated with $\pi, \theta$ as well as $p r$ and $S_{O}$. Of all the invasive populations screened for trematodes and included in this study there were only three reports of $P$. acuta shedding larval trematodes (cercariae) within its invasive range (Table 4); France [105], Spain [106], Iran [107]. None of the cercariae recovered from invasive $P$. acuta populations were characterized genetically, as such only broad taxonomic distinctions can be made; Echinostomatidae (France [105]), Strigeidae (Iran [107]) and Xiphidiocercous cercariae (Spain [106]). Determining origin of infection of invasive $P$. acuta (i.e. spillback versus spillover) is inhibited by a lack of taxonomic resolution. Inclusion of parasite genetic data is required to better understand Physa-trematode invasion dynamics.

Populations from Western Europe (presumably the first invasive populations) and allied populations from the Middle East have the greatest $\pi$ of invasive populations sampled. These data suggest that richness of trematode infection increases positively with background genetic variation and time since invasion, and leads to the prediction that over time as invasive $P$. acuta populations increase in size their role in local trematode transmission will increase. Meta-analysis was limited by population genetic sampling within the invasive range, which will be necessary to more robustly model the relationship between genetic diversity and trematode prevalence.

Overall results from meta-analyses support the 'Enemy-Release' hypothesis [36, 37]. There are numerous explanations for this within the P. acuta - trematode system. Firstly, most founding populations likely consisted of eggs or young snails, as common with the aquarium trade, and were therefore uninfected. Secondly, there might be incompatibility among native parasites and invasive host populations. An additional ecological explanation is that invasive $P$. acuta populations often establish in highly modified habitats (i.e. drainage ditches, man-made water-bodies $[14,87])$, which may not be suitable to sustain a diversity of trematode life cycles. As invasive populations spread over time into a broader range of habitat types, one would expect interaction with wildlife trematode fauna to become more frequent with a greater potential for native parasites to establish in $P$. acuta. For example, in countries such as England and Germany, where the invasion history of $P$. acuta is well documented, initial reports of $P$. acuta are from habitats such as botanical gardens that are known to import aquatic vegetation, but less than a decade 
later, $P$. acuta is reported from natural habitats (summarized by Vinarski [108]).

Apart from directly hosting trematodes, invasive $P$. acuta populations might play a role in diluting or enhancing transmission of indigenous parasites in several ways. Physa acuta may act as a decoy host [109-111] to indigenous trematode species, as it is an efficient competitor to native snails often displacing them to become the dominant gastropod within the community [14, 16]. Dobson [16] showed that following its establishment in Mozambique, $P$. acuta overtook Bulinus forskalii, a primary transmitter of human schistosomiasis (Schistosoma haematobium), as the dominant snail. It has been shown experimentally Schistosoma haematobium can penetrate $P$. acuta in Nigeria, though the parasite cannot reach patency [112]. There are also numerous reports of invasive $P$. acuta acting as a reservoir for larval parasites, specifically as a second intermediate host to trematodes. Similarly, non-host specific larvae of the invasive nematode Angiostrongylus (=Parastrongylus) cantonensis were reported in Saudi Arabia [113] and Egypt [114] from P. acuta.

Host-parasite invasion dynamics are often underappreciated when considering the impact of invasive species, especially when the associated parasites are not causing notable pathology. Most commonly it seems hosts acquire a distinct assemblage of indigenous parasites within their invasive range [36] over time, and the consequences to local transmission and biodiversity are not clear. While the primary goal of this study was to characterize the population genetic structure and invasion history of $P$. acuta, we aim to begin to use this system to address the role of host demographics in the acquisition of local parasite assemblages specifically, to identify potential predictors of parasite invasion success for the purposes of modeling host-parasite invasion over time.

\section{Conclusions}

This study provides improved sampling of Physa acuta within its native range, where mtDNA analyses reveal two phylogenetic clades (A \& B) and previously unknown population structure between the Eastern and Western USA. Increased sampling of native populations allowed the estimation of the invasion history of $P$. acuta. We report evidence for the occurrence of multiple independent invasion events from different source populations across the USA and Eastern Canada. The initial invasion into Western Europe occurred over 200 years ago, with more recent invasions into the Southern Hemisphere (South America, Africa) occurring within the last 20-80 years.

We also examined the relationship between $t s i, p r, S_{o}$ and host-population genetic parameters $(H d, \pi, \theta)$ to identify parameters of relevance for modeling host-parasite invasion dynamics over time. We found a significant positive relationship among $\pi$ with trematode $p r$ and $S_{o}$. These data suggest that, (1) host demographic parameters might be integral in the assembly of parasite communities within invasive host populations and (2) background genetic diversity may be an important parameter to consider in future efforts to model host-parasite invasion dynamics. Overall, our data supports predictions based on the 'Enemy Release hypothesis' [36, 37]. Hosts, particularity snail intermediate hosts, are substantially easier to sample and monitor over time and space relative to their associated trematode assemblages and may prove a valuable and tractable tool to model parasite invasion.

\section{Additional files}

Additional file 1: Physa acuta locality and database information. (XLSX 27 kb)

Additional file 2: Non-Physa acuta locality and database information (XLSX $13 \mathrm{~kb}$ )

Additional file 3: CO1 phylogeny of Physa estimated using Bayesian inference. Posterior probability values $\geq .95$ are shown. Taxon names are reflective of the names assigned to sequences in the original NCBI records. (PDF $14 \mathrm{~kb}$ )

Additional file 4: Concatenated $16+\operatorname{cox} 1$ phylogeny. Branch support values $\geq .95 / 70$ (PP/BS) are shown. Taxon names are reflective of the names assigned to sequences in the original NCBI records. (PDF 165 kb)

Additional file 5: ITS1 phylogeny estimated using Bayesian inference. Physa acuta samples are colored according to the clade they were recovered from based on mitochondrial gene tree analysis: pink = Clade A, green = Clade B. Physa acuta taxa labeled as black did not group within $P$. acuta based on mitochondrial gene trees, and were excluded from all in-group analyses (S17, S120 and all P. zionis samples). ITS1 data only exists for HQ283259 and Pacuta_18S/ITS and were therefore not included in mitochondrial gene tree analyses. Posterior probabilities are illustrated as branch support values. (PDF $143 \mathrm{~kb}$ )

Additional file 6: $16 \mathrm{~S}$ in-group analysis. Taxa are colored according to the FWEC they were collected from. Phylogeny (A) was generated using ML methods and phylogeny (B) was generated using BI. Branch support values $\geq 70$ bootstrap (A) and $\geq .95$ posterior probabilities (B) are denoted by a black circle. (PDF $188 \mathrm{~kb}$ )

Additional File 7: Bayesian Skyline Plots. Effective size over time plots estimated in BEAST using a Bayesian Skyline prior, mean values are shown and confidence values were excluded for clarity. Three mutation rates (per million year): 1\% (solid line), 0.04\% (dashed line) and 4\%(circle line) were tested. (A) Range-wide estimates for North America (NAM, dark grey, $n=79$ ), Central and South America (SAM, lime green, $n=13$ ), Eurasia (EUR, pink, $n=49$ ) and Africa and Oceania (AFOC, blue, $n=7$ ). North America dataset ran for 50,000,000 generations, Eurasia 20,000,000 generations, Central/South America and Africa/Oceania ran for 5,000,000 generations. B. Estimates by FWECs sampled: Rio Grande $(\mathrm{RIO}$, red, $n=16)$, Coastal (COA, blue, $n=13)$, Colorado (COL, purple, $n=11)$, Atlantic (ATL, orange, $n=9$ ), Mississippi (MISS, green, $n=26$ ), the Great Basin and St. Lawrence FWECs were excluded because of low sample size. All FWEC datasets were run for 5,000,000 generations, with the exception of Atlantic $(3000,000)$. C. Estimates of recovered Clades, Clade A (A, aqua, $n=116$ ) and $B(B$, dark green, $n=33)$ compared to total (TOT, light grey, $n=149)$. The total dataset and Clade A ran for $80,000,000$ generations, Clade B ran for $10,000,000$ generations. Bayesian skyline plots were constructed in TRACER, the data was exported and visualized using Excel. (PDF 144 kb)

Additional file 8: Bibliography of published invasion reports. (XLSX $30 \mathrm{~kb}$ )

\section{Abbreviations}

16S: 165 ribosomal subunit; AF: Africa; AIC: Akaike information criterion; AMOVA: Analysis of molecular variance; ATL: Atlantic FWEC; BI: Bayesian inference; BSP: Bayesian skyline plot; C\&S AM: Central and South America; 
COA: Coastal FWEC; COL: Colorado FWEC; cox1: Cytrochrome oxidase I gene; EU: Europe; FWEC: Freshwater ecological complex; GRB: Great Basin FWEC; $H$ : Number of haplotypes; $H d$ : Haplotype diversity; IR: Invasive range; ITS1: Internal transcribed spacer region 1; K: Average sequence divergence; MCMC: Markov chain monte carlo; MD: Middle East; ME: Minimum evolution; MISS: Mississippi FWEC; ML: Maximum likelihood; MSB: Museum of Southwestern Biology; MSN: Minimum spanning network; mtDNA: Mitochondrial DNA; $\mathrm{N}$ : Number of individuals sampled; na: Not applicable; Ne: Effective population size; NR: Native range; NZ/OZ: New Zealand and Australia; pr: Prevalence; RIO: Rio Grande FWEC; S: Segregating site; So: Observed species richness; STL: St. Lawrence FWEC; tsi: Time since invasion; USA: United States of America; Ow: Wattersons estimator per site; $\pi$ : Nucleotide diversity

\section{Acknowledgements}

The authors would like to thank the following people for their help in the collection and/or screening of the snails used in this study: Dr. Ramesh Devkota, Dr. Ben Hanelt, Dr. Norm Davis, Ms. Martina Laidemitt, Mr. John Schlutz. The authors would also like to thank Dr. Charles Criscione and three anonymous reviewers for their helpful comments regarding this manuscript, and Dr. Thomas Turner for helpful suggestions regarding data analysis. We acknowledge technical support from the University of New Mexico Molecular Biology Facility, which is supported by National Institutes of Health, USA grant P30GM110907 from the Institute Development Award program of the National Center for Research Resources, USA. This work was funded through a National Science Foundation, USA grant to SVB (DEB 1021427) and a National Institutes of Health grant R37 Al101438 to ESL.

\section{Funding}

This work was funded through a National Science Foundation, USA grant to SVB (DEB 1021427) and a National Institutes of Health grant to ESL (R37 Al101438).

\section{Availability of data and materials}

The datasets used and/or analyzed during the current study are available from the corresponding author on reasonable request.

\section{Authors' contributions}

ETE collected specimens, analyzed and interpreted the data and wrote the manuscript. ESL collected some of the specimens, partially funded this study, and provided feedback for the manuscript. SVB collected some of the specimens and sequence data, partially funded this study and was a major contributor to the manuscript. All authors have read and approved the final manuscript.

\section{Competing interest}

The authors declare that they have no competing interests.

\section{Ethics approval and consent to participate}

Animal collection and use for this study was in accordance with IACUC under protocol number 16-200327-MC. The species sampled are not endangered or protected.

\section{Publisher's Note}

Springer Nature remains neutral with regard to jurisdictional claims in published maps and institutional affiliations.

\section{Received: 31 August 2017 Accepted: 5 June 2018}

Published online: 03 July 2018

\section{References}

1. Sax D, Kinlan B, Smith K. A conceptual framework for comparing species assemblages in native and exotic habitats. Oikos. 2005;108:457-64.

2. Estoup A, Guillemaund T. Reconstructing routes of invasion using genetic data: why, how and so what? Mol Ecol. 2010;19:4113-30.

3. Facon B, Pointier J-P, Jarne P, Sarda V, David P. High genetic variance in lifehistory strategies within invasive populations by way of multiple introductions. Curr Biol. 2008;18:363-7.

4. Cristescu ME. Genetic reconstructions of invasion history. Mol Ecol. 2015;24:2212-25.

5. Jarne P, Delay B. Population genetics of freshwater snails. Trends Ecol Evol. 1991;6:383-6.
6. Facon B, Pointier JP, Glaubrecht M, Poux C, Jarne P, David P. A molecular phylogeography approach to biological invasions of the new world by parthenogenetic Thiarid snails. Mol Ecol. 2003;12:3027-39.

7. Draparnaud JPR. Histoire naturelle des mollusques terrestres et fluviatiles de la France. 1805

8. Dillon RT, Wethington AR, Rhett JM, Smith TP. Populations of the European freshwater pulmonate Physa acuta are not reproductively isolated from American Physa heterostropha or Physa integra. Invertebr Biol. 2002;121:226-34.

9. Lydeard C, Campbell D, Golz M. Physa acuta Draparnaud, 1805 should be treated as a native of North America, not Europe. Malacologia. 2016;59:347-50.

10. Wethington AR, Lydeard C. A molecular phylogeny of Physidae (Gastropoda: Basommatophora) based on mitochondrial DNA sequences. J Molluscan Stud. 2007;73:241-57.

11. Bousset $L$, Pointier JP, David $P$, Jarne P. Neither variation loss, nor change in selfing rate is associated with the worldwide invasion of Physa acuta from its native North America. Biol Invasions. 2014;16:1769-83.

12. Clampitt PT. The comparative ecology of the snails Physa gyrina and Physa integra (Basommatophora: Physidae). Malacologia. 1970;10:113-51.

13. Monsutti A, Perrin N. Dinucleotide microsatellite loci reveal a high selfing rate in the freshwater snail Physa acuta. Mol Ecol. 1999:8:1076-8.

14. Brackenbury TD, Appleton CC. Recolonization of the Umsindusi River, Natal, South Africa, by the invasive gastropod, Physa acuta (Basommatophora, Physidae). J Med Appl Malacol. 1993;5:39-44.

15. Appleton CC. Alien and invasive fresh water Gastropoda in South Africa. Afr J Aquat Sci. 2003;28:69-81.

16. Dobson M. Replacement of native freshwater snails by the exotic Physa acuta (Gastropoda: Physidae) in southern Mozambique; a possible control mechanism for schistosomiasis. Annals of Tropical Medicine \& Parasitology. 2004;98:543-8.

17. Perrin N. The life history parameters of Physa acuta (Gastropoda, Mollusca) in experimental conditions. Revue Suisse Zoologique. 1986:93:725-36.

18. Say T. Conchology. In: Nicholson W, editor. American Edition. Philadelphia: British Encyclopedia; 1817.

19. Te GA. A Systematic study of the family Physidae (Basommatophora: Pulmonata). Doctor of philosophy dissertation. University of Michigan. Ann Arbor. 1978;

20. Burch JB. North American freshwater snails. Hamburg. Michigan: Malacological Publications; 1989

21. Taylor DW. Introduction to Physidae (Gastropoda: Hygrophila); biogeography, classification. morphology Rev Biol Trop. 2003;

22. Wethington AR, Guralnick R. Are populations of physids from different hot springs distinctive lineages? Am Malacol Bull. 2004;19:135-44.

23. Pip E, Franck JPC. Molecular phylogenetics of Central Canadian Physidae (Pulmonata: Basommatophora). Can J Zool. 2008:86:10-6.

24. Dillon RT Jr, Wethington AR. No-choice mating experiments among six nominal taxa of the subgenus Physella (Basommatophora: Physidae). Heldia. 2004:69-78.

25. Bousset L, Henry PY, Sourrouille P, Jarne P. Population biology of the invasive freshwater snail Physa acuta approached through genetic markers, ecological characterization and demography. Mol Ecol. 2004;13:2023-36.

26. Dillon RT, Wethington AR. The Michigan Physidae revisited: a population genetic survey. Malacologia. 2006;48:133-42.

27. Escobar S, Epinat G, Sarda V, David P. No correlation between inbreeding depression and delayed selfing in the freshwater snail Physa acuta. Evolution. 2007:61:2655-70

28. van Leeuwen CHA, Huig N, van der Velde G, van Aleb TA, Wagemaker CAM, Sherman $\mathrm{CDH}$, Klaassen M, Figuerola J. How did this snail get here? Several dispersal vectors inferred for an aquatic invasive species. Freshw Biol. 2013; 58:88-99.

29. Ghabooli S, Shiganova TA, Zhan A, Cristescu ME, Eghtesadi-Araghi P, Maclsaac HJ. Multiple introductions and invasion pathways for the invasive ctenophore Mnemiopsis leidyi in Eurasia. Biol Invasions. 2011;13:679-90.

30. Dunn AM. Chapter 7 Parasites and Biological Invasions. Natural history of host-parasite interactions. Elsevier. 2009:161-84.

31. Kelly DW, Paterson RA, Townsend CR, Poulin R, Tompkins DM. Parasite spillback: a neglected concept in invasion ecology? Ecology. 2009;90:2047-56.

32. Dunn AM, Hatcher MJ. Parasites and biological invasions: parallels, interactions, and control. Trends Parasitol. 2015:31:189-99.

33. Cichy A, Faltýnková A, Żbikowska E. Cercariae (Trematoda, Digenea) in European freshwater snails - a checklist of records from over one hundred years. Folia Malacologica. 2011;19:165-89. 
34. Gordy MA, Kish L, Tarrabain M, Hanington PC. A comprehensive survey of larval digenean trematodes and their snail hosts in Central Alberta, Canada. Parasitol Res. 2016;115:3867-80.

35. Cribb T, Bray R, Olson P, Timothy D, Littlewood J. Life cycle evolution in the Digenea: a new perspective from phylogeny. Adv Parasitol. 2003;54:197-254.

36. Torchin ME, Lafferty KD, Dobson AP, McKenzie VJ. Introduced species and their missing parasites. Nature. 2003;

37. Keane R. Exotic plant invasions and the enemy release hypothesis. Trends Ecol Evol. 2002;17:164-70.

38. Folmer O, Hoeh WR, Black MB, Vrijenhoek RC. Conserved primers for PCR amplification of mitochondrial DNA from different invertebrate phyla. Mol Mar Biol Biotechnol. 1994;3:294-9.

39. Palumbi S, Martin A, Romano S, McMillan WO, Stice L, Grabowski G. The simple fool's guide to PCR. Honolulu Hawaii. 1991.

40. Larkin MA, Blackshields G, Brown NP, Chenna R. Clustal W and Clustal X version 2.0. Bioinformatics. 2007;23:2946-8.

41. Castresana J. Selection of conserved blocks from multiple alignments for their use in phylogenetic analysis. Mol Biol Evol. 2000;17:540-52.

42. Akaike H. A new look at the statistical model identification. IEEE Trans Automat Contr. 1974;19:716-23.

43. Darriba D, Taboada GL, Doallo R, Posada D. jModelTest 2: more models, new heuristics and parallel computing. Nat Methods. 2012;

44. Swofford DL. PAUP*: phylogenetic analysis using parsimony ( ${ }^{*}$ and Other Methods), version 4.0. Sinauer Associates. USA: Sunderland Massachusetts; 2003.

45. Ronquist F, Huelsenbeck JP. MrBayes 3: Bayesian phylogenetic inference under mixed models. Bioinformatics Oxford University Press. 2003;19:1572-4.

46. Rambaut A, Drummond AJ. Tracer: MCMC trace analysis tool, Version 1.5e. 2009. http://tree.bio.ed.ac.uk/software/tracer/

47. Rambaut A, Drummond A. FigTree v1. 3.1. 2009. http://tree.bio.ed.ac.uk/ software/figtree/

48. Tamura KEA. MEGA5: molecular evolutionary genetic analysis using maximum likelihood, evolutionary distance, and maximum parsimony methods. Mol Biol Evol. 2011;28

49. Shimodaira H. An approximately unbiased test of phylogenetic tree selection. Goldman N, editor Systematic Biology. 2002;51:492-508.

50. Shimodaira H, Hasegawa M. CONSEL: for assessing the confidence of phylogenetic tree selection. Bioinformatics. 2001;17:1246-7.

51. Maddison WP, Maddison DR. Mesquite: a modular system for evolutionary analysis. Version. 2015;04(2015):3.

52. Abell RA. USA WWF. Freshwater ecoregions of north America: Island Press; 2000

53. Maxwell JR, Edwards CJ, Jensen ME, Paustian SJ, Parrott H, Hill DM. A Hierarchical Framework of Aquatic Ecological Units in North America (Nearctic Zone). United States Department of Agriculture, Forest Service; 1995.

54. Librado P, Rozas J. DnaSP v5: a software for comprehensive analysis of DNA polymorphism data. Bioinformatics. 2009;

55. Leigh JW, Bryant D. Popart: full-feature software for haplotype network construction. Nakagawa S, editor. Methods Ecol Evol. 2015;6:1110-6.

56. Excoffier L, Smouse PE, Quattro JM. Analysis of molecular variance inferred from metric distances among DNA haplotypes: application to human mitochondrial DNA restriction data. Genetics. 1992;

57. Excoffier $L$, Lischer HEL. Arlequin suite ver 3.5: a new series of programs to perform population genetics analyses under Linux and windows. Mol Ecol Resour. 2010;10:564-7.

58. Reynolds J, Weir BS, Cockerham CC. Estimation of the coancestry coefficient: basis for a short-term genetic distance. Genetics 1983.

59. Drummond AJ, Rambaut A, Shapiro BE, Pybus OG. Bayesian coalescent inference of past population dynamics from molecular sequences. Mol Biol Evol. 2005;22:1185-92.

60. Drummond AJ, Suchard MA, Xie D, Rambaut A. Bayesian Phylogenetics with BEAUti and the BEAST 1.7. Mol Biol Evol Oxford University Press. 2012;29: 1969-73.

61. Reid DG, Rumbak E, Thomas RH. DNA, morphology and fossils: phylogeny and evolutionary rates of the gastropod genus Littorina. Phil Trans R Soc Lond B The Royal Society. 1996;351:877-95.

62. Crandall ED, Frey MA, Groseberg RK, Barber PH. Contrasting demographic history and phylogeographical patterns in two indo-Pacific gastropods. Mol Ecol. 2008;17:611-26.

63. Panova M, Blakeslee AMH, Miller AW, Mäkinen T, Ruiz GM, Johannesson K et al. Glacial history of the North Atlantic marine snail, Littorina saxatilis, inferred from distribution of mitochondrial DNA lineages. Steinke D, editor PloS ONE. 2011;6:e17511.
64. Harris DJ, Ferreira AF, De Frias Martins AM. High levels of mitochondrial DNA diversity within oxychilid land snails (subgenus Drouetia Gude, 1911) from São Miguel island, Azores. J Molluscan Stud. 2013;79:177-82.

65. Poulin R. Comparison of three estimators of species richness in parasite component communities. J Parasitol. 1998;84:485-90.

66. Laidemitt MR, Zawadzki ET, Brant SV, Mutuku MW, Mkoji GM, Loker ES. Loads of trematodes: discovering hidden diversity of paramphistomoids in Kenyan ruminants. Parasitology. 2017;144:131-47.

67. Evans NA, Gordon DM. Experimental observations on the specificity of Echinoparyphium recurvatum toward second intermediate hosts. Zeitschrift fur Parasitenkunde Springer-Verlag. 1983;69:217-22.

68. McCarthy AM, Kanev I. Pseudechinoparyphium echinatum (Digenea: Echinostomatidae): experimental observations on cercarial specificity toward second intermediate hosts. Parasitology. 1990;100:423-8.

69. Benjamini $Y$, Hochberg $Y$. Controlling the false discovery rate - a practical and powerful approach to multiple testing. Journal of the Royal Statistical Society Series B-Methodological. 1995:57:289-300.

70. Heller R, Chikhi L, Siegismund HR. The confounding effect of population structure on Bayesian skyline plot inferences of demographic history. Mailund T, editor PloS ONE. 2013;8:e62992.

71. Hanson D, Cooke S, Hirano Y, Malaquias MAE, Crocetta F, Valdés Á. Slipping through the cracks: the taxonomic impediment conceals the origin and dispersal of Haminoea japonica, an invasive species with impacts to human health. Hewitt J, editor PloS ONE. 2013;8:e77457.

72. Bayha KM, Chang MH, Mariani CL, Richardson JL, Edwards DL, DeBoer TS, et al. Worldwide phylogeography of the invasive ctenophore Mnemiopsis leidyi (Ctenophora) based on nuclear and mitochondrial DNA data. Biol Invasions. 2015:17:827-50.

73. Lukoschek V, Waycott M, Keogh JS. Relative information content of polymorphic microsatellites and mitochondrial DNA for inferring dispersal and population genetic structure in the olive sea snake, Aipysurus laevis. Mol Ecol. 2008;17:3062-77.

74. Larmuseau MHD, Raeymaekers JAM, Hellemans B, Van Houdt JKJ, Volckaert FAM. Mito-nuclear discordance in the degree of population differentiation in a marine goby. Heredity. 2010;105:532-42.

75. Cristescu MEA, Hebert PDN, Witt JDS, Maclsaac HJ, Grigorovich IA. An invasion history for Cercopagis pengoi based on mitochondrial gene sequences. Limnol Oceanogr. 2001:46:224-9.

76. Städler T, Frye M, Neiman M, Lively CM. Mitochondrial haplotypes and the New Zealand origin of clonal European Potamopyrgus, an invasive aquatic snail. Mol Ecol. 2005;14:2465-73.

77. Lounnas M, Correa AC, Vázquez AA, Dia A, Escobar JS, Nicot A, et al. Self-fertilization, long-distance flash invasion and biogeography shape the population structure of Pseudosuccinea columella at the worldwide scale. Mol Ecol. 2017:26:887-903.

78. Turner RD, Clench WJ. A new blind Physa from Wyoming with notes on its adaptation to the cave environment. The Nautilus. 1974;

79. Rogers DC, Wethington AR. Physa natricina Taylor 1988, junior synonym of Physa acuta draparnaud, 1805 (Pulmonata: Physidae). Zootaxa 2007.

80. Gates KK, Kerans BL, Keebaugh JL, Kalinowski S, Vu N. Taxonomic identity of the endangered Snake River physa, Physa natricina (Pulmonata: Physidae) combining traditional and molecular techniques. Conserv Genet. 2013;14: 159-69.

81. Moore AC, Burch JB, Duda TF. Recognition of a highly restricted freshwater snail lineage (Physidae: Physella) in southeastern Oregon: convergent evolution, historical context, and conservation considerations. Consery Genet. 2015;16:113-23.

82. Forister ML, Fordyce JA, Shapiro AM. Geological barriers and restricted gene flow in the holarctic skipper Hesperia comma (Hesperiidae). Mol Ecol. 2004; 13:3489-99.

83. Finn DS, Theobald DM, Black WC, Poff NL. Spatial population genetic structure and limited dispersal in a Rocky Mountain alpine stream insect. Mol Ecol. 2006;15:3553-66.

84. Hughes JM, Schmidt DJ, FINN DS. Genes in streams: using DNA to understand the movement of freshwater Fauna and Their riverine habitat. Bioscience. 2009:59:573-83.

85. Turner GF. Parallel speciation, despeciation and respeciation: implications for species definition. Fish Fish. 2002:3:225-9.

86. Nolan JR, Bergthorsson U, Adema CM. Physella acuta: atypical mitochondrial gene order among panpulmonates (Gastropoda). J Molluscan Stud. 2014;80:388-99. 
87. AndersonR. Physella (Costatella) acuta Draparnaud in Britain and Ireland-its taxonomy, origins and relationships to other introduced Physidae. J Conchol. 2003;38:7-21.

88. Forbes E. A history of British Mollusca and of their shells Vol. IV. London: John Van Voorst; 1853.

89. Jeffreys JG. British conchology. London: Van Voorst; 1862

90. Oscoz J, Tomás P, Durán C. Review and new records of non-indigenous freshwater invertebrates in the Ebro River basin (Northeast Spain). Aquat Invasions. 2010;5:263-84

91. Reusch TBH, Bolte S, Sparwel M, Moss AG, Javidpour J. Microsatellites reveal origin and genetic diversity of Eurasian invasions by one of the world's most notorious marine invader, Mnemiopsis leidyi (Ctenophora). Mol Ecol. 2010;19:2690-9.

92. Simon A, Britton R, Gozlan R, van Oosterhout C, Volckaert FAM, Hänfling B. Invasive cyprinid fish in Europe originate from the single introduction of an admixed source population followed by a complex pattern of spread. Steinke D, editor. PloS ONE. 2011;6:e18560.

93. Posada D, Crandall K. Intraspecific gene genealogies: trees grafting into networks. Trends Ecol Evol. 2001;16:37-45.

94. De Kock KN, Wolmarans CT. A re-evaluation of the occurrence of freshwater molluscs in the Kruger national park. Koedoe. 1998;41:1-8.

95. De Kock KN, Wolmarans CT, Preez Du LH. Freshwater mollusc diversity in the Kruger National Park: a comparison between a period of prolonged drought and a period of exceptionally high rainfall. Koedoe. 2002;45:1-11.

96. Curtis BA. Freshwater macro-invertebrates of Namibia. Modoqua. 1991; 17:164-87.

97. Mohamed F, Najat M. Co-occurrence de Physa acuta Draparnaud et vecteurs intermédiaires de la bilharziose au Maroc. Riv Idrobiol. 1998;37:169-77.

98. Fashuyi SA. Freshwater gastropod molluscs in Ondo state, Nigeria. J Afr Zool. 1990;104:165-70.

99. Brown DS. Freshwater snails of Africa and their medical importance: Taylor and Francis; 1980

100. Paraense WL, Pointier J-P. Physa acuta Draparnaud, 1805 (Gastropoda: Physidae): a study of topotypic specimens. Memórias do Instituto Oswaldo Cruz Fundação Oswaldo Cruz. 2003;98:513-7.

101. Collado GA. Unraveling cryptic invasion of a freshwater snail in Chile based on molecular and morphological data. Biodiversity and conservation. 2nd ed. Springer Netherlands. 2016;26:567-78.

102. Albrecht C, Kroll O, Moreno Terrazas E, Wilke T. Invasion of ancient Lake Titicaca by the globally invasive Physa acuta (Gastropoda: Pulmonata: Hygrophila). Biol Invasions. 2008;11:1821-6.

103. Hui Ng T, Kiat Tan S, Yeo DCJ. Clarifying the identity of the long-established, globally-invasive Physa acuta Draparnaud, 1805 (Gastropoda: Physidae) in Singapore. Bio Invasions Records. 2015;4:189-94.

104. Avise JC. Phylogeogrpahy: the history and formation of species. Harvard University press. 2000;

105. Dreyfuss $G$, Vignoles P, Abrous M, Rondelaud D. Unusual snail species involved in the transmission of Fasciola hepatica in watercress beds in Central France. Parasite. 2002;9:113-20.

106. Toledo R, Munoz-Antoli C, Perez M, Esteban JG. Larval trematode infections in freshwater gastropods from the Albufera Natural Park in Spain. J Helminthol. 1998;72:79-82.

107. Athari A, Gohar-Dehi S, Rostami-Jalilian M. Determination of definitive and intermediate hosts of cercarial dermatitis-producing agents in northern Iran. Arch Iran Med. 2006;9:11-5.

108. Vinarski MV. The history of an invasion: phases of the explosive spread of the physid snail Physella acuta through Europe, Transcaucasia and Central Asia. Biol Invasions. 2017;19:1299-314.

109. Yousif F, el-Emam M, el-Sayed K. Effect of six non-target snails on Schistosoma mansoni miracidial host finding and infection of Biomphalaria alexandrina under laboratory conditions. J Egypt Soc Parasitol 1998;28:559-568.

110. Munoz-Antoli C, Trelis M, Gozalbo M, Toledo R, Haberl B, Esteban JG. Interactions related to non-host snails in the host-finding process of Euparyphium albuferensis and Echinostoma friedi (Trematoda : Echinostomatidae) miracidia. Parasitol Res. 2003;91:353-6.

111. Chipev NH. Decoy effect and host infection by miracidia within snail communities. Parasitology. 2009;106:265-76.

112. Akinwale OP, Kane RA, Rollinson D, Stothard JR, Ajayi MB, Akande DO, et al. Molecular approaches to the identification of Bulinus species in south-West Nigeria and observations on natural snail infections with schistosomes. J Helminthol. 2011;85:283-93.
113. Bin Dajem SM. Freshwater snails in Asser region, Saudi Arabia with special refernce to the zoonotic trematode. J Egypt Soc Parasitol. 2009;39:551-7.

114. Abo-Madyan AA, Morsy TA, Motawea SM, Garhy El MF, Massoud AMA. Spot light survey on fresh-water snails of medical importance in Al Fayoum governorate. Egypt J Egypt Soc Parasitol. 2005;35:49-58.

115. Lozek V. Quartarmollusken der Tschechoslwakie Rozpravy ustredniho. Ustavu geolickeho. 1964;31:1-374.

116. Stelfox AW. Lists of land and freshwater molluscs of Ireland. Proc R Ir Acad. 1911;29B:65-164.

117. Welch RJ. Foregin Physa, Ards, county down. Irish Naturalists Journal. 1930;3:91.

118. Kerney MP. Atlas of the non-marine Mollusca of the British Isles. Huntingdon: Conchological Society of Great Britain and Ireland and the Biological Records Centre; 1976.

119. Ellis MB. British snails (1969 reprint). Oxford: Claredon Press; 1926.

\section{Ready to submit your research? Choose BMC and benefit from:}

- fast, convenient online submission

- thorough peer review by experienced researchers in your field

- rapid publication on acceptance

- support for research data, including large and complex data types

- gold Open Access which fosters wider collaboration and increased citations

- maximum visibility for your research: over $100 \mathrm{M}$ website views per year

At BMC, research is always in progress.

Learn more biomedcentral.com/submissions 